\title{
Appreciating Formal and Informal Knowledge Transfer Practices within Creative Festival Organizations
}

\begin{abstract}
Purpose - Problem-solving approaches to research have dominated the not-for-profit festival management field. Little attention has been paid to how festival organizations successfully create cultures where knowledge transfer is practised within the high intensity of a festival lifecycle.

Drawing upon insights from Social Practice Theory and Appreciative Inquiry (AI), our purpose in this article is to offer a different conceptual approach to understanding how knowledge transfer 'works' as an organizational practice to produce a collaborative festival culture.
\end{abstract}

Design/methodology/approach - This article draws upon an ethnographic case study with the highly acclaimed Queensland Music Festival organization in Australia. The research questions and methods were framed around an appreciative approach that identified formal and informal practices that 'worked' rather than a conventional problem focused analysis.

Findings - Our research focused on appreciating the cultural context that shaped the interrelationships between formal and informal knowledge transfer practices that enabled trust and collaboration. We identified a range of knowledge transfer practices that contributed to the creation of a shared festival ethos and the on-going sustainability of the festival vision.

Practical implications - The not-for-profit sector brings numerous challenges for festival organizations and there is a need to appreciate how collaborative and creative knowledge transfer can occur formally and informally. Festival organizers can benefit from understanding the relational and practice dimensions of knowledge management as they are performed within specific organisational contexts.

Originality/value - An appreciative understanding of knowledge transfer practices has not yet been applied to not-for-profit festival organizations where problem-solving approaches dominate the field. Article classification - Research paper 
Key words - Appreciative Inquiry, Social Practice Theory, knowledge transfer practices, not-forprofit organizations, creative festival organizations, ethnography

\section{Introduction}

Not-for-profit creative festivals face particular challenges with regard to practising knowledge transfer within a dynamic organizational context and short time frames for the production of cultural events (Abfalter et al., 2012, Ragsdell et al., 2014, Stadler et al., 2014). While many not-for-profit organizations experience negative impacts from time pressures and high staff turnover, little attention has been paid to how festival organizations successfully create cultures where knowledge transfer and collaboration occur within the high intensity of a festival lifecycle. In contrast to the problem-solving and psychological approaches to research that have dominated the event management field, this article draws upon Appreciative Inquiry (AI) to understand how knowledge transfer 'works' between organizational actors as formal and informal practices that produce a collaborative festival culture. Our purpose in this article is to identify how organizational 'know-how' was enacted through the interrelationships between formal and informal transfer practices within a case study of the Queensland Music Festival (QMF). We examine how the knowledge and practice know-how that enables collaboration is transferred not only in formal settings such as meetings, but also through informal contexts that can be conceptualised in terms of organisational practices where work is performed, ordered and interpreted (such as lunchroom conversations). We suggest that formal and informal contexts of knowledge transfer are best understood within the dynamics of organisational culture rather than as an individualised exchange of information between employees. As Erden et al (2014: 712) explain, "Social practices are situationally constituted, recurrent, materially bounded, and shared forms of social activities that produce and structure life in organizations."

In particular informal practices can enable (or undermine) the interpretation of formal knowledge transfer practices: rituals of lunch time interaction allow staff members to further discuss ideas, refine, 
accept or reject them outside the formal context. Conflict, miscommunication and related issues are evident in most non-profit organizations; however, the use of an appreciative approach can focus attention on a more nuanced understanding of how staff members construct meaning through their work practices and relationships. Hence we argue that an AI approach to festival research frames inquiry in ways that are reflective of an ethos within many non-profit organizations where value is placed upon the creation of knowledge through democratic processes where power is shared and collaborative culture is fostered. Rather than merely focussing on formal practices and processes of knowledge transfer, not-for-profit festival organizers can benefit from recognizing collaboration as a relational knowledge practice that each organizational actor performs through formal/informal contexts where information is shared (or withheld) across the festival lifecycle.

The article is structured as follows: we first discuss the importance of knowledge transfer practices in not-for-profit and creative festival organizations in terms of what a practice oriented theoretical approach can contribute to the literature. Appreciative Inquiry is then introduced as a different way of framing inquiry and research questions about knowledge transfer in these organizations. We then move on to our methodology, including a brief description of the case under study, the methods and appreciative analytical approach. The findings identify how formal practices shaped the development of a shared understanding of the festival activities, such as the role played by central staff team meetings. We also identify the significance of informal practices that facilitated the sharing and interpretation of diverse responsibilities, such as individuals from different teams having lunch together. We finish off with a discussion of how a deeper appreciation of knowledge transfer is enabled through the interrelationships between formal and informal practices as key organisational processes. We identify several implications for festival organizers in relation to the recognition of how formal and informal knowledge transfer practices can be supported by organizations for longterm success. 


\section{Knowledge transfer practices in creative festival organizations}

Not-for-profit festival organizations experience unique challenges with regards to knowledge transfer practices. Knowledge transfer is often used interchangeably with knowledge sharing, however, knowledge transfer implies a more complex understanding of how actors interpret and apply what they have learnt from others; it also involves the "acquisition and application of knowledge by the recipient" (Wang and Noe, 2010: 117). We argue for a greater conceptual emphasis on the organisational context that shapes 'how' knowledge transfer is practised rather than a more technical, psychological or functionalist view of information exchange. In this way we draw upon the insights of social practice theory (Feldman \& Orlikowski 2011, Reckwitz, 2002) that locates the construction of meaning in the performance of organizational tasks and relationships where actors are connected through tacit and explicit meanings, competences and materials. We propose a practice-based understanding of knowledge transfer, where practices “(...) refer to routines, procedures, and established ways of doing things that have become normal like a habit (...). They tend to be repeated with certain periodicity such that organizational participants would come to anticipate the occurrence of those routines or procedures at the prescribed time and place" (Thatchenkery and Chowdhry, 2007: 61). Hence, we argue that knowledge transfer in festival organizations is performed as a creative and relational social practice, involving professionals and volunteers with different backgrounds coming together for only a short period of time who share their artistic and operational know-how to create the festival experience. The "pulsating nature" (Hanlon and Cuskelly, 2002: 231) of festival organizations creates challenges with regards to knowledge transfer processes and practices across the festival lifecycle for both permanent and seasonal staff. All staff in diverse teams require a shared understanding of the festival culture, organizational identity and operational strategies in order to be able to work together effectively. During the short period of time of the festival, however, not everything about festival practices and processes can be documented and stored, and thus made explicit. 
In terms of longer term knowledge transfer, every festival organization requires a strategic plan in order to sustain momentum given the fact that individual staff members leave once the festival is over. The current festival management literature identifies these issues (Getz, 2002, Allen et al., 2011, Abfalter et al., 2012, Ragsdell et al., 2014), yet the relational and practice-based dimensions of knowledge transfer are still under researched, as identified elsewhere (Stadler et al., 2014). This article aims to contribute a different conceptual approach to understanding within event management about how knowledge is produced through organizational practices and interpretive processes that are shaped by power relations and organizational cultures within not-for-profit organizations (LeclercquVandelannoitte, 2011). In this Foucauldian sense, power is understood to be 'productive' of different knowledge practices (rather than a zero-sum equation) and underpins collaboration and information sharing as everyday organizational matters. Conventionally, event management research has focused on when 'things' go wrong (relational power is either ignored or understood as simply structural) rather than exploring how the actors within festival organizations manage to successfully collaborate in contexts with limited resources and high pressure. Hence, we argue that knowledge transfer is better understood as a social practice and shaped by relations of power that constitute the dynamic nature of organizational culture (Leclercqu-Vandelannoitte, 2011).

Despite a vast interest in knowledge management in the private and public sectors over the last decades, current research on information and knowledge management in not-for-profit organizations such as most festival organizations - is limited to a few studies (see for example, Lettieri et al., 2004, Hurley and Green, 2005, Hume et al., 2012, Ragsdell et al., 2014). In festivals and events more specifically, research has predominantly focussed on traditional information and knowledge management approaches such as storing and documenting information in databases and checklists (Getz, 2007, Singh et al., 2007, Allen et al., 2011). Although very valuable, the conceptualisation of managing knowledge in creative festival organizations needs to move beyond the assumption that what organizations do is primarily rational information management. In festival organizations, a limited number of particular knowledge transfer studies have been undertaken that identify the 
everyday interpretive processes through which festival staff produce and share knowledge about what enables and constrains their work. Katzeff and Ware (2006) identified a storytelling video booth as a useful practice tool for gathering and transferring knowledge about the challenges of volunteer management and developing an inclusive culture. Their festival case study faced particular challenges with regards to preserving experiences and transferring volunteers' knowledge from one year to the next. Through the use of a storytelling video booth, narratives were collected that provided insight into the culture of the festival organization as well as what newcomers needed to learn in order to become members of the festival community. Abfalter et al (2012) investigated knowledge sharing through the development of a community-of-practice within a festival organization that enabled ongoing transfer and multiple forms of interpretation across the festival team. Results highlighted different levels of participation in work and knowledge sharing practices classified along four groups: the core group, active group, peripheral group and outsider group. Knowledge transfer practices within these groups included for example formal and informal meetings, training and mentoring practices; whereas knowledge transfer between the groups was facilitated though meetings and evaluation and debrief practices. Ragsdell et al (2014) examined how project knowledge was acquired, stored and shared within a volunteer-led festival organization and found that 'learning-bydoing' approaches were common processes enabling knowledge transfer. Formal training and record keeping was lacking, however, strong emphasis was placed on informal social knowledge practices, such as master-apprentice approaches to learning. The authors also demonstrated how trust in the management of the event and in the quality of project knowledge, as well as motivation and pride in doing a good job were among the factors positively influencing knowledge transfer behaviour among volunteers. Ragsdell and Jepson (2014) investigated volunteers' knowledge sharing activities within three Campaign for Real Ale (CAMRA) festivals and identified several inhibitors and enablers to knowledge sharing as well as individual, organizational and technological barriers to knowledge sharing in particular. With the exception of these studies that explore the performance, interpretation and relational practices of knowledge management and transfer, the primary emphasis within the literature has been on knowledge as an 'asset' that can be stored, documented and rationally communicated. We highlight how knowledge transfer in creative festival organizations is a significant 
organizational practice that is central to achieving successful outcomes within a multidisciplinary performance context.

Within the festival and events management, as well as the knowledge management literature there also is an overemphasis on problem identification and solutions to the challenges of knowledge transfer. For example, problems that have been identified are the nature of volunteer work and job rotation in the industry that make it difficult to share and retain knowledge in the long term, as well as lack of formal processes of knowledge transfer in small to medium sized organizations (Ragsdell et al., 2014). While these issues need to be explored, a problem-solving approach to research tends to maintain the status quo and is centred on 'fighting fires' within the limits of a problem saturated frame of reference (Nyaupane and Poudel, 2012). Such an approach does not enable researchers to step outside the problem focus to explore different understandings of issues and visions for the future that could underpin a different organizational culture and effective knowledge transfer. In contrast to conventional approaches we argue that the insights from Appreciative Inquiry provide researchers with novel ways of thinking about characteristics that can support effective knowledge management practices by highlighting 'what works' within these organizations. All too often organizations take for granted the relations of trust, collaboration and knowledge sharing upon which productivity, success and innovation are built. Successful knowledge transfer can be assumed to 'naturally' occur when organisations appear to be operating well but, without an understanding of how organisational practices shape outcomes when problems arise, the result can all too often be individualised blame. Appreciative Inquiry can offer a way of identifying what aspects of organisational culture and practice are important to maintain and develop, as well as areas that require change.

\section{Appreciative Inquiry}

Festivals create celebratory experiences of culture and community through the performance of traditions and new practices of engagement and creativity. Appreciative Inquiry (AI) is an approach (both a specific methodology and broader social constructionist epistemology) within organizational 
studies and management that identifies how stories of success and achievement can contribute to understanding how culture and identity are co-constructed by organisational actors. By identifying stories about positive experiences AI aims to identify what is already working well in an organization and at the same time, challenges and problems are framed as opportunities for learning (Cooperrider and Whitney, 1999). AI is based upon social constructionist underpinnings that Cooperrider and Whitney (1999) identify in terms of five principles:

1. The constructionist principle assumes that the organization is best understood as a living entity, where relationships are productive of knowledge, and world is interpreted through the mediating effects of language.

2. The simultaneity principle assumes that inquiry into organizational processes and change occur together.

3. The poetic principle assumes that actors within the organization co-author and narrate the organizational identity in everyday contexts. Stories are interpreted and construct meaning, learning and knowledge.

4. The anticipatory principle assumes that when positive images of future change are articulated they will influence current actions, relationships and directions in a similar way.

5. The positive principle assumes that framing questions about possibilities, future desires and stories will provide the momentum for change.

The AI approach aims to recognise and build on the successes of an organization by exploring its current culture, desired values and future identity (Thatchenkery and Chowdhry, 2007, Van Tiem and Rosenzweig, 2006, Whitney and Trosten-Bloom, 2003). The positive focus in AI does not mean that conflict and problems are ignored throughout the process. Instead a focus on the analyses of problems and suggested solutions, issues and challenges are framed as opportunities for learning and reflexive thinking (Van der Haar and Hosking, 2004, Whitney and Trosten-Bloom, 2003). Thatchenkery and Chowdhry (2007: 33) applied AI to knowledge sharing and highlighted how, "[b]eing appreciative is 
harder than finding problems. To be appreciative, we must experience a situation, accept the situation, make sense of the situation (pros/cons), and do a bit of mental gymnastics to understand the situation with an appreciative lens." According to the authors, organizations of all shapes and sizes (including not-for-profit organizations) can benefit from this approach as it is "nonthreatening and accepting (...) [and] makes people realize what they do can make a difference" (Thatchenkery and Chowdhry, 2007: 153). They also maintained that appreciative sharing of knowledge is a prospective rather than retrospective approach, hence it is aimed at identifying what individuals, groups and organizations need to consider within their current culture in order to achieve a shared vision. In terms of knowledge management this more democratic approach enables different voices within an organization to be articulated and recognized as valuable sources of contextual understanding (beyond a rational model of information sharing). Drawing upon the principles of an AI approach in researching 'what works' within an organization requires an exploration of how knowledge transfer practices have relevance to the organizational actors who perform them in relation to the broader organizational context. For example, the day to day practices of paid and volunteer staff within festival organizations are structured by the overarching time frame and schedule, as well as the micro level details of the numerous public facing events and back stage activities. Hence, an AI approach to researching festival organizations within the not-for-profit sector highlights the interconnected relationships and power relations that actors negotiate through a mix of formal and informal knowledge transfer practices (from regular meetings to interactions over lunch) as they produce (or undermine) a collaborative organizational culture. Next we turn to the organizational context and explain the research methodology that we used to identify knowledge transfer practices through an AI framework.

\section{Methodology}

An ethnographic case study with the Queensland Music Festival (QMF) in Australia was conducted from February - August 2011. The QMF is a 17 day long biennial music festival that is centrally organized in the city of Brisbane and performed through numerous events held across the city and 
more distant, regional communities in Queensland. With multiple sponsors and other sources of funding the festival works through community cultural development principles to realise a vision of "transforming lives through unforgettable musical experiences." QMF staff members are required to work with different communities over an extended period of time and encourage their participation in performing a local arts event. The festival is managed by a permanent paid staff of seven people and supported by another 35 production, administrative and marketing professionals, as well as over 2,000 international, national and community-based artists during each festival season (QMF, 2011). It thus represents an organizational structure typical of large festivals, and faces the challenge of bringing festival members with various backgrounds together for a concentrated period of time. The research was approved by the QMF executive director, QMF board of directors and Griffith University Human Ethics Committee.

Applying ethnographic research methods (participant observation and in-depth interviews) over seven months allowed the first author to immerse herself in the festival experience, to become part of the organization and to critically investigate knowledge transfer practices from the perspective of different staff members and teams (O'Reilly, 2005). She participated in meetings, rehearsals and similar events from February - August 2011 - and helped out with day-to-day tasks at the festival headquarters in Brisbane, while also observing events at two local and regional sites. Field notes were taken during and after all observations describing the settings, events, informal conversations with participants as well as the ethnographer's feelings, challenges and learning processes. She also conducted 28 in-depth interviews with festival members in a range of different roles - permanent as well as seasonal staff members, board members, artists, contractors and members of the communities. Through the research process particular attention was paid to how the organizational culture supported or impeded collaboration with respect to the festival identity and vision, and how staff members negotiated knowledge transfer practices between the central organizing team and the regional event teams. 
During the early stages of the ethnography the first author identified many positive interactions and practices that contributed to a collaborative QMF culture. Deadlines were achieved, staff were highly committed and the festival programme was successfully organized. The initial research focus which sought to identify key problems within the high pressured context of a not-for-profit organization proved to be limiting in terms of understanding the dynamics underpinning success. Hence, the research focus on what was working well emerged around an appreciative approach (rather than as a methodological protocol) that identified the formal and informal organizational practices that staff engaged in collaboratively in order to ensure a complex range of tasks were completed and creative decisions made. Applying insights from an AI approach allowed the framing of questions in an appreciative rather than a conventionally critical way (Michael, 2005). While AI is mainly used in management practice as an action research tool and a step-by-step process to identify 'what is', 'what might be', 'what could be' and finally 'what will be' (see Cooperrider and Whitney, 1999 for details on the 4-D cycle), this was not the framework for our research. The AI approach 'emerged' through the ethnography, rather than being a planned 'intervention' with the organization from the start. The first author noticed in formal as well as informal conversations with festival staff members how they frequently referred to what was important to them, and with passion talked about the ethos and values of the festival organization. The similarities to AI became apparent, in relation to how, through the AI approach, positive stories are shared about what people value, what is important to them and what they hope for in the future (Cooperrider and Whitney, 1999). The first author therefore started to adopt Michael's (2005) suggestion of using AI as an interview tool for field research where an emphasis on stories can provide valuable insights into a community's values and beliefs. Michael (2005: 226) found that through asking her participants to recount stories of what worked well, they “(...) were eager to tell their stories; offered dynamic and unrehearsed information; and spoke more openly, with less defensiveness or fear of reprisal." The framing of interview questions in our research and deeper probing within informal discussions encouraged similar reflections, 'What has been your best experience with QMF so far?;' 'Do you feel you belong to the festival community?;' 'Can you 
describe the friendships and relationships you have developed with members of the community/other staff members?' Interview questions explored participants' own stories and range of experiences which resulted in a strong focus on the positive, collaborative culture of QMF.

The AI approach to research has been widely applied in a range of different organizational settings as well as in tourism and hospitality research (Koster and Lemelin, 2009, Raymond and Hall, 2008), community development (Finegold et al., 2002, Morsillo and Fisher, 2007) and knowledge management (Thatchenkery and Chowdhry, 2007). However, it has not been used in festival and event management research thus far, particularly not in relation to knowledge transfer in not-for-profit creative organizations. While we did not aim to go through the entire AI process or use AI as an action research tool, AI principles influenced the way interviews were conducted and analysis was undertaken by both authors. Based on Whitney et al.'s (2010) analysis throughout the AI process in order to compile an 'inventory of strengths', we identified in our analysis what worked well within QMF and which situations caused staff members to be at their best in relation to knowledge transfer practices they engaged in. This approach was congruent with the festival's community cultural development ethos that emphasised research with people rather than on people (Eikhof and Haunschild, 2007, Horton et al., 2014). A traditional critical analysis, on the other hand, would only emphasise problems and issues; it overlooks the positive factors and values that are necessary for the life and long-term success of the organization (Cooperrider and Whitney, 1999). The benefits of an AI approach are echoed by Carter (2006: 51) who recounted how, “(...) 'research-as-celebration' or 'working with what's working well' was compelling; it resonated with the way that I work with people and with the values that I hold as a researcher, practitioner and individual." The first author was able to develop rapport with her participants, to become 'one of them' and share the festival organizational culture, which allowed the identification of problems, tensions and issues in a supportive environment. AI was particularly useful for framing the analysis of the little known and taken for granted knowledge transfer practices that are central to the strategic focus and day to day operations of the central festival team as they work closely with local event teams in diverse locations 
across Queensland. The potential for things to go wrong with the complex range of festival logistics, time lines and relationships was enormous and yet within QMF problems were resolved effectively and efficiently.

\section{Findings}

In regards to the question of how knowledge transfer was practised within QMF, we found that staff members engaged in both formal and informal work practices that enabled effective collaboration which in turn was crucial to the success of the festival. Staff members, however, mainly took these practices for granted as a tacit part of their day to day work and did not explicitly identify them through the language of 'knowledge transfer'. Yet, there was an overwhelming range of stories that emphasised the collaborative 'know how' that staff brought with them from other festival work or developed through their involvement in QMF over time (sometimes several seasons). We outline the formal practices through which staff developed a shared festival knowledge (understanding their own role in relation to the greater whole), such as how central staff team meetings were managed to facilitate the performance of specific and collective identities (projects, actors and festival vision) over time. Organizations typically create information sharing rituals through meetings (Smith and Stewart, 2011), however, they are not necessarily effective ways to formalise knowledge, make tacit knowledge explicit or generate new knowledge through collaboration. Staff meetings are organizational practices that can elicit frustration, boredom and power-knowledge struggles over the representation of key issues, resourcing, strategy and interpersonal differences. In the not-for-profit sector in particular, organizations frequently face funding and time pressures as well as high turnover of voluntary staff and hence knowledge fragmentation that can exacerbate problems related to effective knowledge sharing (Lettieri et al., 2004, Hume et al., 2012, Ragsdell et al., 2014). Through the research we also identified the significance of informal practices that facilitated the interpretation of information and the performance of trust relationships that underpinned knowledge transfer. For example, the practice of individuals from different teams having lunch together allowed differences to be identified and resolved while generating mutual support through pleasurable shared activity 
(eating). In a time pressured context, the informal opportunities for interaction, relationship building and sharing of past/present experiences were importantly interrelated with the formal organizational practices in fostering understanding of 'how things are done within QMF'. The management of the festival meetings, strategy and teams facilitated a culture of collaboration that effectively mobilised organisational formal and informal practices - rather than relying upon either individual agency (actor responsibility for jobs) or organisational structure (managing through hierarchies of expertise). In the following sections we explore how organizational actors and the ethnographer transferred knowledge between formal settings and also informal contexts. Recognizing the role of informal practices enables a deeper appreciation of how knowledge sharing is performed and embodied as a collaborative practice that requires the ongoing interpretation and discussion of ideas that are refined, accepted or rejected outside of the formal context (Lahti et al., 2002, Allen et al, 2007). Yet the importance of these informal practices is oftentimes overlooked in the high pressure work environments of not-for-profit organisations, despite perennial issues such as stress and burnout. The findings reveal how an AI approach allowed us to identify important meaning making aspects of such informal practices.

Staff meetings: Performing trust, expertise and collegiality

Staff meetings were an important, yet taken for granted knowledge practice within the QMF organization in terms of both formal and informal transfer of knowledge as well as constituting staff members' know-how that enabled working within QMF's collaborative culture. The QMF full staff meetings started in February 2011 and were held fortnightly on Tuesday mornings, then weekly coming closer to the festival. At first, only the permanent staff and a few seasonal staff members attended the meetings (approximately 15 people total), then as the team expanded week by week, more and more staff members came along; by May 2011 all 35 professionals at the festival headquarters attended the weekly meetings. The entire team knew the schedule of the meetings and it was also forwarded to the ethnographer. Everybody present at the office on the days of the meeting was expected to attend. Approaching the festival deadline, management emphasized that there would 
only be "a quick one, as we know you're all busy" (field notes, 26/05/11), reflecting the need to effectively manage time in the stressful festival environment. The suggested order of topics to be discussed was laid down in advance and it was the same for every staff meeting: Artistic Director; Executive Director; Programme Update; Technical Update; Marketing and Development Update; Finance and Administration; and Any other business. The formal order of the staff meetings, however, was frequently mixed up indicating a collaborative and informal give-and-take approach to the meetings rather than only one-way delivery. Give-and-take is common in many not-for-profit organizations when meetings are conducted (Deal and Kennedy, 1982), demonstrating how democratic processes inform the development of collaborative cultures. An organisational culture that supports high employee commitment and collaboration is crucial for knowledge transfer to effectively be practised (Yang, 2007; Suppiah and Singh Sandhu, 2011). In this case the productive use of power was evident in the collegial forms of interaction that were fostered alongside the emphasis on sharing expertise (technical, creative, logistical) on a 'need to know' basis for the whole team. In this respect the 'transfer' of knowledge within QMF could be better reframed as a ritualised 'performance' where actors were able to creatively improvise with the organisation script to identify what needed to 'be known'. Central to this performative practice was the cultivation of collegiality (using humour) that in turn supported the development of trust between actors reliant upon each other's different expertise. It became clear that trust was crucial in the improvised performance where the elements of knowing, not knowing and not needing to know were significant in the practice of transferring knowledge.

The atmosphere is very casual. Somebody brought chocolate and is passing it around. One of the ladies is fixing her hair while she is talking, and others start doing the same when it is their turn. Gary introduces himself and says that he - unfortunately - doesn't have enough hair to make it look good. Everyone laughs. Then Gary goes on to tell us about some recent changes he's made to the system. Somebody interrupts, "Gary, spare us the technical details... I don't have a clue what you're talking about." Again, there's laughter in the room. "No worries, guys, just give it a go whenever you have a minute and let me know if you have any questions!" Gary quickly moves on to the next item on his list... (field notes, 03/02/11) 
The informal atmosphere in the staff meeting described above enhanced relationships and trust between staff members and helped them become comfortable to ask questions, provide input and cocreate their work (Wang et al., 2006, Thatchenkery and Chowdhry, 2007). In terms of knowledge transfer therefore, the staff meetings were an opportunity for knowledge transfer to be practised among the team in two ways: firstly, a structure to the meetings was provided in which everybody shared information and knowledge, and secondly, at the same time a comfortable and collaborative atmosphere was created within which staff members were willing to share their insights and ideas. A collaborative culture is difficult to create and maintain within creative and temporary festival organizations (Stadler et al., 2013) as staff members only work together for a short period of time and are not necessarily able to develop trust and strong working relationships. Within QMF, however, effective collaboration was identified and explicitly stated as crucial for the success of the organization.

Catching Up: Kitchens, hallways and lunch

Frequent informal talks in the hallway, the kitchen or during lunch also supported collaboration within QMF and enhanced staff members' understanding of who was working on what and how they performed their roles. Information, experiences and stories were exchanged quickly while staff members were making coffee or walked in and out of the office. Informal and spontaneous conversations are highly valuable in terms of knowledge transfer (Orr, 1996, Yang, 2007, Hecker, 2012, Zundel, 2013) and within QMF created an ethos of sharing and creative collaboration. The first author also learned about current events as well as about 'how things are done within QMF' through talking to staff members in the hallway, the kitchen or during lunch and, once rehearsals started, even behind the stage.

I'm lucky to run into Gary in the kitchen. He's making coffee and asks if I want one too. Oh yes, I'm always up for a coffee. We move to the board room and start talking about this and that. I mention that I took a look at the database and the new system after what was discussed in today's meeting. Gary smiles... "Does it make any sense to you at all?!" I can sense his passion for technology and his mission to make all systems more 
efficient as well as user-friendly. With excitement I tell him how easy it was to find information on a particular artist when Anne asked me to look up his travel arrangements. Gary's face lights up and he proudly goes on to tell me how difficult it was to work with last year's database and how far they've come with the new one already... (field notes, 03/02/11)

Being part of the organization was important for the ethnographer in regards to learning 'how things are done within QMF' and gaining the know-how that was necessary not only for the research process but also in order to develop trust with the team and understand the festival culture and identity. Engaging in informal knowledge transfer practices was a vital element underpinning this process, through which she soon switched from using 'they' to 'we' in her field notes demonstrating her sense of belonging to the team and knowing 'how to' be one of them. Furthermore, in regards to gaining know-how about particular events and the broader festival context, certain things only started to make sense as she informally expressed her perspective and questions to others and they collectively created meaning around them (Dixon, 1999). In the example above, engaging in the informal practice of sharing a coffee with another staff member allowed the first author to follow up with a question and gain a deeper sense of what was discussed in the more formal meeting. The appreciative approach she thereby implemented was important in developing rapport with the staff member and sharing his passion and excitement for the job.

Even though emphasis in meetings was placed on positive stories and stories of success, challenges and issues did arise at key points. During the Programme Update in one of the staff meetings, for example, a challenging situation was discussed:

Veronica gives a brief summary of what happened last week. She looks exhausted. It sounds like there were some issues with her project. "I've already met with Maria yesterday and we managed to sort a few things out, so no need to go through all of it again today." Sarah wants to know if it was a creative issue or a set-up issue?! "Mainly a creative issue," Veronica says and - with a smile on her face - tells everyone that she already has a plan for dealing with it. Two of the other producers offer their advice and propose an alternative idea. It doesn't quite make sense to me, I don't know a lot about Veronica's project at this stage, but I can relate to Sarah's comment, "Life would be so 
much easier without having to deal with artists, wouldn't it?!" Laughter all around... (field notes, 11/05/11)

In response to the challenges, emotional labour (Korczynski, 2003, Odio et al., 2013), and issues the staff member had to face, the atmosphere created in the meeting was encouraging and solution oriented. Other staff members offered help and advice, however, some members of the team did not know enough about the project in order to be able to contribute. Similarly, for the first author the situation only became clearer a week later when she met with two staff members (from different teams) in the kitchen to prepare lunch and engaged in an informal conversation:

Stella comes in to prepare lunch too and the two of them have a chat while I'm just standing there listening. I then explain that I would love to be part of at least one project of every team, even if it is just a small one. Veronica likes the idea and asks me whether I know anything about her team's projects. I confess that I only have a basic idea at this point, because there are too many things going on at the same time. Both of them agree, Stella says she only knows about her group's projects, not about everybody else's. Veronica agrees, yes, it is a challenge to understand everything because everyone is so busy working on their own projects. She starts explaining what "her" projects are about: The one I am particularly interested in is called [...]. It will take place on the opening night of the festival at the Old Museum in Brisbane. It is based on a children's story which will be turned into a stage performance. Originally they wanted to have dancers from QUT [Queensland University of Technology] and also some kids dancing. But then a lot of the dancers dropped out and - rolling her eyes - Veronica says they had to adjust their ideas quite a bit within a certain budget, which was a big challenge. They had a casting for other dancers, then decided to do a theatrical performance with only a few dancers involved. Veronica takes a deep breath after recounting all the troubles they had. I wasn't aware of all these challenges before, but some of the discussions I've heard at last week's staff meeting now start to make sense. (field notes, 18/05/11)

Being part of the team and sharing lunch with them gave the first author an opportunity to engage in informal conversations and practices through which valuable know-how was exchanged among the team - stories and experiences which she would not necessarily have heard in formal interviews, nor by asking staff members to talk about problems and issues. Rather, in the example above, she casually expressed her excitement and interest in the project. This allowed the two staff members to share the latest developments of their projects and they - without being asked to do so - recounted some of the issues they had to face. The ethnographer, like a staff member, came to understand not only 'what' the 
different projects were about but also 'how' team members were performing their tasks. Having lunch together hence formed an important knowledge enabler that shifted trust relationships beyond signified office boundaries (with particular role responsibilities and identities), which was similar to what Thatchenkery and Chowdhry (2007: 86) called "coffee talk." The practice was informal and mainly taken for granted within the organizational culture, but it created a particular affective atmosphere of collaboration and sense of belonging that helped to counter some of stresses associated with running a festival. Participants also recognised that it was crucial to support each other and to "make people aware of what you're up to and being aware of what people around you are up to as well" (interview 6). Informal conversations and transfer of knowledge over lunch or coffee enhanced this process among the team. Similar to what Orlikowski (2002: 260) identified as "knowing the players in the game through face to face interaction", sharing lunch was a key knowledge transfer practice within QMF that not only allowed sharing information, but also building social relationships that increased trust and commitment to the organization.

Getting on with it: Improvisation in knowledge transfer practices

Over time, the staff meetings became shorter because approaching the festival season, staff members were 'getting on with' tasks and engaged in a large number of day-to-day activities. At this point staff members already knew 'how to' collaborate and 'how to do things within QMF' and thus began to transfer knowledge more informally and immediately as deadlines arose. Moreover, the team meetings then provided an opportunity to discuss details of 'how to' do certain tasks rather than 'what' needed to be done more generally. The change from formal staff meetings to team meetings also demonstrates how the QMF team structure enabled seasonal staff members to engage in their own decision making practices. The festival event projects were clearly distributed among the teams, and there was no need any more to know everything else that was going on with other projects. Sharing everything with everyone would only lead to information overload, which can be dangerous, particularly when everybody is already busy (Cranwell-Ward and Abbey, 2005). In an interview after 
the festival, a staff member confirmed this observation. The QMF team structure was identified as more effective than the large staff meetings that he had experienced with other festival organizations:

Do you feel that everybody was on the same page most of the time?

Peter: Some things I think not everybody has to be on the same page for. Like, we have a [team] structure for a reason. If you're doing Drag Queensland [a community project staged in Brisbane], you don't need to know what's going on in Bowen [community project in regional Queensland] really... Like, what would be the point? A lot of festivals have these giant staff meetings, where everyone sits there and says what he's doing. But you don't have the time and you don't really want to know that a forklift is arriving in Bowen on Thursday, if you're doing Drag Queensland in Brisbane. What's the point? (interview 27)

The formal knowledge transfer practices in the staff meetings represented the challenging and everchanging context of the festival life cycle, where the team grew and expanded week by week approaching the festival season. More and more staff members attended the meetings from February to June 2011. Then, at a certain point, the meetings stopped; however, this formal work practice demonstrated how the team learned 'how to' work together, the collaborative atmosphere and the formal as well as informal transfer of crucial knowledge in practice. In the example above, Peter went on to say, "if you really needed to know about the forklift in Bowen, you can just pick up the phone and call Emma. She's in charge and we all know she knows what she's doing" (interview 27). Emma had attended the previous staff meeting where an update was provided on her particular project. Other staff members learned what she was working on and after having established a relationship of trust, felt comfortable discussing further details with her over the phone.

In the staff meetings particularly the collaborative culture of the organization was observed in relation to the trust relationships that had been established. Trust relationships between staff members are crucial with regards to helping them become comfortable to ask questions and provide input; processes and practices through which the informal transfer of knowledge can be enhanced (Wang et al, 2006; Thatchenkery and Chowdhry, 2007; Fleig-Palmer and Schoorman, 2011), however, they are 
difficult to develop in short-term and intense work environments. At QMF, trust was created during the formal meetings through a unique dynamic that involved 'know how' about the sharing (and withholding) of festival information. Providing too much information posed the risk of undermining trust (wasting people's precious time), just as the provision of not enough information could jeopardise effective knowledge sharing (understanding the relational nature between projects and central operations). Formal meetings provided the basis for a shared understanding of 'how to' collaborate within QMF; however, it was the interrelationship with informal knowledge sharing that facilitated the ongoing development of trust and mutual support.

Informal knowledge transfer practices within QMF provided opportunities for 'relationships of care' to be developed and enhanced, which in turn contributed to staff members feeling comfortable to share information and knowledge as part of the creative process. These care relationships are crucial knowledge enablers in not-for-profit organizations where trust, commitment, passion and motivation are, on the one hand, central to the ethos of collaboration, yet on the other hand, they are difficult to maintain within an intense and resource limited work environment (Hurley and Green, 2005, Ragsdell et al., 2014). Within QMF, having lunch together and other informal work practices formed an important part of creating trust where power was exercised in the form of care relationships. Hence, it is important to understand how informal knowledge transfer practices are enacted in context specific relationships (for example, mediated by food rituals) that constitute know-how through enjoyable collaboration. The satisfaction that festival employees derived from working in a not-for-profit festival organization was evident in the narratives that emphasised positive relationships, creative processes and the success of performances.

\section{Summary of Findings}

In contrast to a conventional problem-solving approach within knowledge management that seeks to diagnose problems and offer external solutions, our research focused on appreciating the cultural 
context that shaped the formal and informal knowledge transfer practices that supported collaboration. In this way we contribute to furthering understanding of how festivals as not-for-profit organizations actively support (or impede) the development of collaborative relationships within time pressured and resource limited contexts. While many not-for-profit organizations experience negative impacts from such pressures, the QMF is one example of how a festival organization has developed knowledge transfer practices that facilitate staff engagement, trust, care and collaboration. We identified a range of formal and informal organizational practices that created a means to connected diverse actors at the micro level of work, while also generating a macro level, shared identification with a festival vision that linked the diverse program of events. While organizational conflicts and communication problems were evident, the use of an AI framework enabled a more nuanced focus on how festival staff in the central and project teams negotiated differences in expertise and skill to generate opportunities for learning and reflexive thinking. AI pays attention to what is already working in organizational cultures and how organizational actors construct meaning through their interactions and work relationships; hence we argue that using an AI approach to festival research also reflects an ethos of creating knowledge through democratic processes.

Appreciating 'what works' within an organization, rather than merely aiming to solve immediate problems, can facilitate more conscious reflection on the creation of a collaborative organizational culture that builds upon past successes. QMF staff members effectively transferred knowledge through formal and informal practices, yet the meanings that constitute practices were largely tacit, taken for granted and not recognised as contributing to the success of the organization. Through ethnographic research, we aimed to make explicit these taken for granted practices as a means of documenting 'how' organizations can benefit from understanding the interplay of culture, structure and performance of work in specific contexts (Feldman and Orlikowski, 2011). AI allowed us to focus on the strengths of QMF's knowledge transfer practices rather than merely highlighting problems and aiming to implement solutions. A problem-solving approach would only maintain the status quo (Eikhof and Haunschild, 2007), whereas through applying AI, we were able to identify the positive 
context of formal and informal knowledge transfer practices and hence contribute to the ongoing sustainability of the festival's vision and ethos (Carter, 2006).

\section{Limitations}

While we have identified key knowledge transfer practices that have contributed to the success of the QMF we also note with caution the danger of simply applying such insights to all not-for-profit organizations. Thatchenkery and Chowdhry (2007: 154) describe the necessity of developing a context specific understanding of the relationship between organizational cultures and knowledge transfer practices,

As you can see by the various applications of ASK [Appreciative Sharing of Knowledge] in the private, public, and service organizations, ASK is not a 'one size fits all' approach. Rather, it is a framework that allows for customized solutions to knowledge management challenges. There are a wide variety of ways to apply it so that it makes sense in the organization in which you are working. Recognizing that most organizations have the internal capabilities and talents to respond to their constantly emerging challenges, ASK is a methodology that helps bring those successful elements latent in the organization to the forefront.

\section{Implications for practitioners and researchers}

The not-for-profit sector brings numerous challenges for festival organizations and there is a need to appreciate how collaborative and creative knowledge transfer works to dynamically shape organizational life and occurs through both formal and informal practices. Hence, we theorise our findings in relation to three key principles informed by social practice theory, '(1) that situated actions are consequential in the production of social life, (2) that dualisms are rejected as a way of theorizing, and (3) that relations are mutually constitutive. These principles cannot be taken singly, but implicate one another' (Feldman and Orlikowski, 2011: 1241). One of the key findings from this research was the close interrelationship between formal and informal practices that enabled trust relations between actors with different disciplinary expertise and skills, through ordered yet flexible, routine yet improvised, and professional yet humorous performances. For example, the structure and timing of 
formal staff meetings were adapted to the changing requirements for knowledge transfer across the whole festival team (sharing mirco level expertise became less important). In addition, the importance of informal practices shifted from trust building to the creation of support as the stress and pressure of meeting project deadlines increased through the festival planning (the emotional labour involved with managing creative staff). The interaction between organizational practices contributed to the continual renewal of the organizational culture and work programmes that reinforced a collaborative festival ethos that was simultaneously 'bottom up and top down'.

An appreciative understanding of knowledge transfer practices has not yet been applied to not-forprofit festival organizations where problem-solving approaches dominate the field. Yet the AI approach allowed us to recognize not only formal, but importantly the interrelationship with informal knowledge transfer practices that form the basis for effective collaboration within a not-for-profit organization. Our identification of the importance of trust as it underpins the interrelationships between formal and informal knowledge transfer practices may be useful for festival organizers as they consider the importance of attending to the relational dimension of knowledge management across strategic, operational and creative domains. For example, informal knowledge transfer practices can be supported through valuing (and providing) lunch events, spaces and common times to encourage staff members to further discuss and negotiate ideas beyond the formal context. Applying an AI perspective may allow festival organizers to make explicit the know-how about 'how much to share, when and when not to share' that is necessary for a collective understanding and the development of trust relationships. Sharing everything with everyone is time consuming and not possible in not-for-profit creative festival organizations where funding and time pressures as well as high staff turnover are commonplace. Collaboration is evidently a relational knowledge practice that each organizational actor learns to enact in the context of collegial (or other less engaging) cultures and this in turn develops know-how that is performed and collectively shared over time. A relational understanding of knowledge practices (creation, sharing, transfer) can assist not-for-profit organizations to facilitate the productive exercise of power by employees and managers who 
commonly experience high levels of pressure and limited resources. Our research has aimed to demonstrate the value of an appreciative approach in revealing how collaborative organizational cultures are performed, shaped and managed through democratic knowledge practices that reflect the ethos of many not-for-profit organizations. 


\section{References}

Abfalter, D., Stadler, R. and Mueller, J. (2012), "The Organization of Knowledge Sharing at the Colorado Music Festival”, International Journal of Arts Management, Vol. 14, No. 3, pp. 415.

Allen, J., James, A. D., and Gamlen, P. (2007), "Formal versus informal knowledge networks in R\&D: a case study using social network analysis", $R \& D$ Management, Vol. 37, No. 3, pp. 179-196.

Allen, J., O'Toole, W., McDonnell, I. and Harris, R. (2011), Festival and Special Event Management, John Wiley \& Sons, Ltd., Milton, Qld.

Carter, B. (2006), “'One expertise among many'-working appreciatively to make miracles instead of finding problems - Using appreciative inquiry as a way of reframing research", Journal of Research in Nursing, Vol. 11, No. 1, pp. 48-63.

Cooperrider, D. L. and Whitney, D. (1999), Collaborating for Change: Appreciative Inquiry, available from Books $24 \times 7$, http://common.books24x7.com.libraryproxy.griffith.edu.au/toc.aspx? bookid $=4605$ (accessed 5 December 2012)

Cranwell-Ward, J. and Abbey, A. (2005), Organizational Stress, Palgrave Macmillan, Hampshire \& New York.

Deal, T. E. and Kennedy, A. A. (1982), Corporate Cultures - The Rites and Rituals of Corporate Life, Addison-Wesley Publishing Company, Reading et al.

Dixon, N. M. (1999), The Organizational Learning Cycle - How We Can Learn Collectively, Gower, Hampshire and Vermont.

Eikhof, D. R. and Haunschild, A. (2007), "For art's sake! Artistic and economic logics in creative production", Journal of Organizational Behavior, Vol. 28, No. 5, pp. 523-538.

Erden, Z., Schneider, A., and von Krogh, G. (2014), "The multifaceted nature of social practices: A review of the perspectives on practice-based theory building about organizations", European Management Journal, Vol. 32, No. 5, pp. 712-722.

Feldman, M. S., and Orlikowski, W. J. (2011), "Theorizing practice and practising theory", Organization Science, Vol. 22, No. 5, pp. 1240-1253.

Finegold, M. A., Holland, B. M. and Lingham, T. (2002), "Appreciative Inquiry and Public Dialogue: An Approach to Community Change", Public Organization Review: A Global Journal, Vol. 2, No. 3, pp. 235-252.

Fleig-Palmer, M. and Schoorman, F. D. (2011), "Trust as a Moderator of the Relationship Between Mentoring and Knowledge Transfer", Journal of Leadership \& Organizational Studies, Vol. 18, No. 3, pp. 334-343.

Getz, D. (2002), "Why Festivals Fail”, Event Management, Vol. 7, No. 4, pp. 209-219.

Getz, D. (2007), Event Studies - Theory, Research and Policy for Planned Events, ButterworthHeinemann, Amsterdam et al.

Hanlon, C. and Cuskelly, G. (2002), "Pulsating Major Sport Event Organizations: A Framework for Inducting Managerial Personnel", Event Management, Vol. 7, No. 3, pp. 231-243.

Hecker, A. (2012), "Knowledge Beyond the Individual? Making Sense of a Notion of Collective Knowledge in Organization Theory", Organization Studies, Vol. 33, No. 3, pp. 423-445.

Horton, K. E., Bayerl, P. S. and Jacobs, G. (2014), "Identity conflicts at work: An integrative framework", Journal of Organizational Behavior, Vol. 35, No. S1, pp. 6-22.

Hume, C., Clarke, P. and Hume, M. (2012), "The role of knowledge management in the large non profit firm: building a framework for KM success", International Journal of Organisational Behaviour, Vol. 17, No. 3, pp. 82-104.

Hurley, T. A. and Green, C. W. (2005), "Knowledge management and the nonprofit industry: A within and between approach", Journal of Knowledge Management Practice, Vol. 6, No. 1.

Katzeff, C. and Ware, V. (2006), "Video Storytelling as Mediation of Organizational Learning", Paper presented at the NordiCHI2006: Changing Roles Conference, Oslo.

Korczynski, M. (2003), "Communities of Coping: Collective Emotional Labour in Service Work", Organization, Vol. 10, No. 1, pp. 55-79. 
Koster, R. L. P. and Lemelin, R. H. (2009), “Appreciative Inquiry and Rural Tourism: A Case Study from Canada", Tourism Geographies, Vol. 11, No. 2, pp. 256-269.

Lahti, R. K., Darr, E. D., and Krebs, V. E. (2002), "Developing the productivity of a dynamic workforce: The impact of informal knowledge transfer", Journal of Organizational Excellence, Vol. 21, No. 2, pp. 13-21.

Leclercqu-Vandelannoitte, A. (2011), "Organizations as Discursive Constructions: A Foucauldian Approach”, Organization Studies, Vol. 32, No. 9, pp. 1247-1271.

Lettieri, E., Borga, F. and Savoldelli, A. (2004), "Knowledge management in non-profit organizations", Journal of Knowledge Management, Vol. 8, No. 6, pp. 16-30.

Michael, S. (2005), "The promise of appreciative inquiry as an interview tool for field research", Development in Practice, Vol. 15, No. 2, pp. 222-230.

Morsillo, J. and Fisher, A. (2007), "Appreciative inquiry with youth to create meaningful community projects", The Australian Community Psychologist, Vol. 9, No. 1, pp. 47-61.

Nyaupane, G. P. and Poudel, S. (2012), "Application of appreciative inquiry in tourism research in rural communities", Tourism Management, Vol. 33, No. 4, pp. 978-987.

Odio, M. A., Walker, M., and Kim, M. (2013), "Examining the Stress and Coping Process of MegaEvent Employees", International Journal of Event and Festival Management, Vol. 4, No. 2, pp. $140-155$.

O'Reilly, K. (2005), Ethnographic Methods, Routledge, London and New York.

Orlikowski, W. J. (2002), "Knowing in Practice: Enacting a Collective Capability in Distributed Organizing", Organization Science, Vol. 13, No. 3, pp, 249-273.

Orr, J. E. (1996), Talking About Machines - An Ethnography of a Modern Job, Cornell University Press, Itaca and London.

QMF (2011), Queensland Music Festival, available from http://qmf.org.au/ (accessed 20 September 2011).

Ragsdell, G., Espinet, E. O. and Norris, M. (2014), "Knowledge management in the voluntary sector: a focus on sharing project know-how and expertise", Knowledge Management Research \& Practice, Vol. 12, pp. 351-361.

Ragsdell, G. and Jepson, A. S. (2014), "Knowledge sharing: insights from Campaign for Real Ale (CAMRA) festival volunteers", International Journal of Event and Festival Management, Vol. 5, No. 3, pp. 279 - 296.

Raymond, E. M. and Hall, M. C. (2008), "The Potential for Appreciative Inquiry in Tourism Research", Current Issues in Tourism, Vol. 11, No. 3, pp. 281-292.

Reckwitz, A. (2002), Toward a theory of social practices a development in culturalist theorizing. European Journal of Social Theory, Vol. 5, No. 2, pp. 243-263.

Singh, N., Racherla, P. and Hu, C. (2007), "Knowledge Mapping for Safe Festivals and Events: An Ontological Approach", Event Management, Vol. 11, No. 1-2, pp. 71-80.

Smith, A. C. T. and Stewart, B. (2011), "Organizational Rituals: Features, Functions and Mechanisms", International Journal of Management Reviews, Vol. 13, No. 2, pp. 113-133.

Stadler, R., Reid, S. and Fullagar, S. (2013), "An ethnographic exploration of knowledge practices within the Queensland Music Festival", International Journal of Event and Festival Management, Vol. 4, No. 2, pp. 90-106.

Stadler, R., Fullagar, S. and Reid, S. (2014), "The professionalization of festival organizations: A relational approach to knowledge management", Event Management, Vol. 18, No. 1, pp. 3952.

Suppiah, V., and Singh Sandhu, M. (2011), "Organisational culture's influence on tacit knowledgesharing behaviour", Journal of Knowledge Management, Vol. 15, No. 3, pp. 462-477.

Thatchenkery, T. and Chowdhry, D. (2007), Appreciative Inquiry and Knowledge Management - A Social Constructionist Perspective, Edward Elgar, Cheltenham \& Northhampton.

Van der Haar, D. and Hosking, D. M. (2004), "Evaluating Appreciative Inquiry: A Relational Constructionist Perspective", Human Relations, Vol. 57, No. 8, pp. 1017-1036.

Van Tiem, D. and Rosenzweig, J. (2006), Appreciative Inquiry. Available from Books24x7, http://common.books24x7.com.libraryproxy.griffith.edu.au/toc.aspx ?bookid=12865 (accessed 21 September 2013). 
Wang, J.-K., Ashleigh, M. and Meyer, E. (2006), "Knowledge sharing and team trustworthiness: it's all about social ties!” Knowledge Management Research \& Practice, Vol. 4, No. 3, pp. 175186.

Wang, S., and Noe, R. A. (2010), "Knowledge sharing: A review and directions for future research", Human Resource Management Review, Vol. 20, No. 2, pp. 115-131.

Whitney, D. and Trosten-Bloom, A. (2003), The Power of Appreciative Inquiry - A Practical Guide to Positive Change, Berrett-Koehler Publsihers, Inc., San Francisco.

Whitney, D., Trosten-Bloom, A., and Rader, K. (2010), Appreciative Leadership: Focus on What Works to Drive Winning Performance and Build a Thriving Organization, New York et al.: McGraw-Hill.

Yang, J.-T. (2007), "Knowledge sharing: Investigating appropriate leadership roles and collaborative culture", Tourism Management, Vol. 28, No. 2, pp. 530-543.

Zundel, M. (2013), "Walking to learn: Rethinking reflection for management learning", Management Learning, Vol. 44, No. 2, pp. 109-126. 